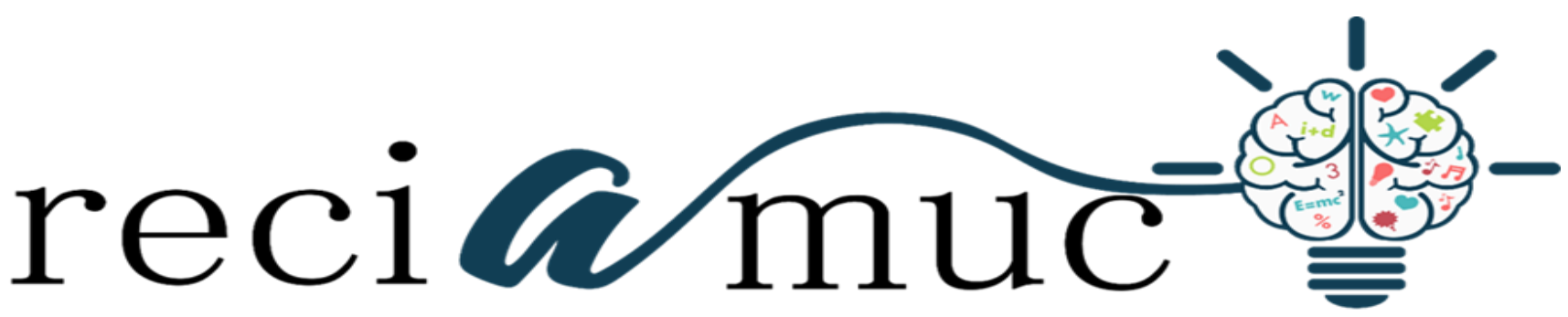

Revista cientifica de investigación actualización del mundo de las ciencias

Miguel Andre Zapata Mata a; Rubí Alisba Borja Torres b; José Ignacio Macías Alcívar $^{\text {c; }}$ Erika Claribel Albán Estrada ${ }^{d}$

Medidas asociadas a la reducción del riesgo de cáncer de cuello uterino

Measures associated with reducing the risk of cervical cancer

Revista Científica de Investigación actualización del mundo de las Ciencias. Vol. 3 núm., 1, enero, ISSN: 2588-0748, 2018, pp. 127-146

DOI: $10.26820 /$ reciamuc/3.(1).enero.2019.127-146

URL: $\underline{\text { http://reciamuc.com/index.php/RECIAMUC/article/view/226 }}$

Código UNESCO: 3205 Medicina Interna

Tipo de Investigación: Artículo de Revisión

Editorial Saberes del Conocimiento

Recibido: 10/12/2018

Aceptado: 20/01/2019

Publicado: 30/01/2019

Correspondencia: mianzamat@hotmail.com
a. Médico; mianzamat@ hotmail.com; Guayaquil, Ecuador.
b. Médico; rubi1981@ hotmail.com; Guayaquil, Ecuador.
c. Médico; joseig.89escritor@hotmail.com; Guayaquil, Ecuador.
d. Médico; ekaalban25@gmail.com; Guayaquil, Ecuador. 


\section{Medidas asociadas a la reducción del riesgo de cáncer de cuello uterino}

Vol. 3, núm. 1., (2019)

Miguel Andre Zapata Mata; Rubí Alisba Borja Torres; José Ignacio Macías Alcívar; Erika Claribel Albán Estrada

\section{RESUMEN}

El cáncer de cuello uterino (CCU) es el segundo tipo de cáncer en mujeres que ocupan regiones menos desarrolladas en todo el mundo. Es una enfermedad prevenible por lo tanto es imperioso los esfuerzos que puedan realizarse en este tema. La presente investigación plasma todo lo relativo a las medidas asociadas a la reducción del riesgo de contraer cáncer de cuello uterino. Para su desarrollo se llevó a cabo una revisión de material documental bibliográfico actualizado. Existen factores de riesgo que predisponen la aparición de esta enfermedad, la tríada que constituye la base sobre la prevención del CCU está formada por la vacuna del VPH, la detección temprana de lesiones precancerosas y el tratamiento de estas. En conclusión, son fundamentales las campañas de vacunación contra el VPH según los lineamientos de la Organización Mundial de la Salud (OMS), brindar la información necesaria a la población femenina y el acceso a los servicios de salud que puedan detectar tempranamente un precáncer, así como las herramientas para su tratamiento pueden reducir los márgenes desastrosos de esta problemática de salud mundial y brindar una mejor calidad de vida a las mujeres en todo el mundo.

Palabras Claves: Prevención; Medidas; Riesgo; Cáncer; Uterino. 


\section{Medidas asociadas a la reducción del riesgo de cáncer de cuello uterino}

Vol. 3, núm. 1., (2019)

Miguel Andre Zapata Mata; Rubí Alisba Borja Torres; José Ignacio Macías Alcívar; Erika

Claribel Albán Estrada

Cervical cancer (CCU) is the second type of cancer in women who occupy less developed regions throughout the world. It is a preventable disease therefore it is imperative the efforts that can be made in this subject. The present investigation captures everything related to the measures associated with the reduction of the risk of cervical cancer. For its development a review of updated bibliographic documentary material was carried out. There are risk factors that predispose the onset of this disease, the triad that forms the basis on the prevention of CCU is formed by the HPV vaccine, the early detection of precancerous lesions and the treatment of these. In conclusion, vaccination campaigns against HPV according to the guidelines of the World Health Organization (WHO), providing the necessary information to the female population and access to health services that can detect a pre-cancer early, are essential. how the tools for their treatment can reduce the disastrous margins of this global health problem and provide a better quality of life for women around the world.

Key Words: Prevention; Measures; Risk; Cancer; Uterine.

\section{Introducción.}




\section{Medidas asociadas a la reducción del riesgo de cáncer de cuello uterino}

Vol. 3, núm. 1., (2019)

Miguel Andre Zapata Mata; Rubí Alisba Borja Torres; José Ignacio Macías Alcívar; Erika Claribel Albán Estrada

El cáncer de cuello uterino es una enfermedad que se origina por el virus de papiloma humano (VPH). Su medio de contagio es por contacto sexual. Por lo general, el propio organismo de la mayoría de las mujeres está en la capacidad de luchar contra la infección de VPH, no obstante, en algunas oportunidades este virus acarrea un cáncer. (Biblioteca Nacional de Medicina de los Estados Unidos, 2018)

Existen factores de riesgos que aumentan la posibilidad de tener la enfermedad, sin embargo, esto no significa que la persona necesariamente se enfermará de cáncer; así como no presentar ningún factor de riesgo tampoco significa que la persona no se enfermará de cáncer. Existen factores que predisponen la enfermedad tales como estar infectado por el virus del papiloma humano (VPH), el cual constituye el factor de riesgo más importante. Otro factor lo constituye el haber estado expuesto al medicamento DES (dietilestilbestrol) en el vientre de la madre. En el caso de tener una infección por el VPH, también existen otros factores que aunados pueden propiciar el cáncer de cuello uterino como lo son el dar a luz a muchos hijos, el tabaquismo (fumar cigarrillos), el hecho de consumir algunos anticonceptivos orales por un largo periodo. Por otra parte, existen factores de riesgo que aumentan el riesgo de infección por el VPH tales como tener un sistema inmunitario debilitado motivado a una inmunodepresión. Las relaciones sexuales a temprana edad y el hecho de tener muchas parejas sexuales también pueden aumentar el riesgo de contraer VPH y aumentar el riesgo de cáncer de cuello uterino. (Instituto Nacional del Cáncer de los Estados Unidos, 2019)

El cáncer cervicouterino (CCU) o cáncer de cuello uterino es causado por la infección por determinados tipos de VPH los cuales son transmitidos por vía sexual. Existen dos clasificaciones de PVH (16 y 18) los cuales son los causantes del 70\% de los CCU, así como de 


\section{Medidas asociadas a la reducción del riesgo de cáncer de cuello uterino}

Vol. 3, núm. 1., (2019)

Miguel Andre Zapata Mata; Rubí Alisba Borja Torres; José Ignacio Macías Alcívar; Erika

Claribel Albán Estrada

algunas lesiones precancerosas. Asimismo, existen datos que relacionan los VPH con cánceres del ano, de la vulva, de vagina y del pene. "El CCU es el segundo tipo de cáncer más frecuente en las mujeres de las regiones menos desarrolladas, donde se estima que en 2018 hubo unos 570.000 nuevos casos (el 84\% de los nuevos casos mundiales)". También en el año 2018, murieron de CCU alrededor de 311.000 mujeres, de las cuales, más del $85 \%$ se produjeron en países de ingresos bajos y medios. (Organización Mundial de la Salud, 2019)

En cuanto a las tasas de mortalidad por cáncer de cuello uterino tenemos que "son tres veces más altas en América Latina y el Caribe que en América del Norte..., ...se prevé que el número de muertes en las Américas aumente un 45\% para 2030”, estos datos en base al Informe Final sobre el Estrategia Regional y Plan de Acción para la Prevención y el Control del Cáncer Cervicouterino. (Organización Panamericana de la Salud, 2017)

El cáncer de cuello uterino es una enfermedad prevenible si se toman en cuenta sus factores de riesgo y se trabaja en base a la reducción de los mismos. La causa fundamental es la infección por alguno de los virus oncogénicos de la familia del virus del papiloma humano (VPH). La ventaja de esta infección radica en que, desde su aparición hasta su cronificación, en la mayor parte de los casos existe una larga evolución hasta la aparición de lesiones premalignas o precancerosas y el posterior desarrollo del cáncer invasor. Es por esta razón que tanto la prevención como la detección temprana es la mejor arma para su tratamiento y erradicación. (Sociedad Española de Oncología Médica, 2018)

En este sentido, la presente investigación tiene como propósito fundamental plasmar información actualizada acerca de las medidas asociadas a la reducción del riesgo de contraer 


\section{Medidas asociadas a la reducción del riesgo de cáncer de cuello uterino}

Vol. 3, núm. 1., (2019)

Miguel Andre Zapata Mata; Rubí Alisba Borja Torres; José Ignacio Macías Alcívar; Erika Claribel Albán Estrada

cáncer de cuello uterino, así como el estudio de los factores de estos riesgos y de estas medidas de prevención en sí. Existen estudios similares, sin embargo, acerca de una enfermedad tan importante a nivel mundial, es imperioso la constante actualización que puede manejarse, la educación continua que pueda brindarse a los profesionales de la salud y la concientización que se intente lograr en la población en general.

\section{Materiales y métodos.}

Se realizó una revisión bibliográfica de fuentes de información relacionadas con la prevención del CCU, sus factores de riesgo y las principales medidas asociadas a la reducción de estos riesgos. El período de búsqueda se realizó entre el año 2014 y el año 2019, a los fines de mantener el principio de actualidad y diferenciar la investigación por su contenido más novedoso ya que existen variadas investigaciones generales orientadas al tema de la prevención de este tipo de cáncer.

Al respecto, Ríos (2017) afirma que la investigación documental “...recurre a la consulta de documentos para obtener sus resultados”. (p. 81). En este sentido, la presente investigación se clasifica por su metodología como una investigación de tipo documental por la fuente usada para su realización.

\section{Resultados.}




\section{Medidas asociadas a la reducción del riesgo de cáncer de cuello uterino}

Vol. 3, núm. 1., (2019)

Miguel Andre Zapata Mata; Rubí Alisba Borja Torres; José Ignacio Macías Alcívar; Erika

Claribel Albán Estrada

Resulta importante, antes de establecer las medidas de reducción de riesgos de contraer CCU, estudiar los factores de estos riesgos, esto es, toda aquella condición que esté vinculada a una mayor probabilidad de que aparezca la enfermedad. Existen factores de riesgos controlables, sobre los cuales se puede trabajar en la prevención y otros no controlables, sin embargo, de tomar en cuenta a la hora de delimitar una población susceptible de padecer la enfermedad.

\section{Factores de riesgos de CCU}

“La forma más común de cáncer de cuello uterino comienza con cambios precancerosos, y existen maneras de detener el origen de esta enfermedad". Todos los esfuerzos deben estar orientados a la prevención tanto de precánceres, como la de cánceres. (American Cáncer Society, 2019)

A continuación, algunos de los factores de riesgos más importantes:

Infección por virus del papiloma humano (VPH)

El factor de riesgo más importante del CCU es la infección por el virus del papiloma humano (VPH, o HPV). Se trata de un grupo de más de 150 virus relacionados, Su medio de transmisión de una persona a otra puede ser durante el contacto con la piel, puede ser mediante la actividad sexual, (sexo vaginal, anal y oral). Existen un grupo de VPH llamados de bajo riesgo los cuales rara vez están relacionados con el cáncer, estos se caracterizan por causar verrugas en diferentes partes del cuerpo, como las manos y los pies, los labios o la lengua, alrededor de los órganos genitales femeninos y masculinos, y el área del ano. Existe otro grupo de VPH llamados 


\section{Medidas asociadas a la reducción del riesgo de cáncer de cuello uterino}

Vol. 3, núm. 1., (2019)

Miguel Andre Zapata Mata; Rubí Alisba Borja Torres; José Ignacio Macías Alcívar; Erika Claribel Albán Estrada

de alto riesgo, por su fuerte vinculación con cánceres, estos incluyen el cáncer de cuello uterino. (American Cancer Society, 2016)

\section{Tabaquismo}

El fumar, tanto activa como pasivamente, expone a las personas a sustancias químicas cancerígenas capaces de afectar no solamente a los pulmones, sino a otros órganos. Se ha encontrado que las mujeres fumadoras poseen casi el doble de probabilidades de padecer CCU. "Se han detectado subproductos del tabaco en la mucosidad cervical de mujeres fumadoras. Los investigadores creen que estas sustancias dañan el ADN de las células en el cuello uterino y pueden contribuir al origen del cáncer de cuello uterino”. Al fumar además se ocasiona que el sistema inmunitario sea menos eficaz para combatir las infecciones con VPH, impidiendo que el organismo por sí solo actúe contra la enfermedad y aumentando el riesgo potencialmente de que se convierta en cáncer. (American Cancer Society, 2016)

"Entre las mujeres infectadas por el VPH, aquellas que fuman o fumaron cigarrillos tienen una incidencia aproximadamente 2 a 3 veces mayor de presentar una neoplasia intraepitelial de grado alto o cáncer invasor". Igualmente, el tabaquismo pasivo también se vincula con aumento de riesgo, pero en menor medida. (Instituto Nacional del Cáncer de los Estados Unidos, 2019)

El contenido perjudicial del tabaco daña las células del organismo y provocan el crecimiento del cáncer. No solo el fumar, también otros usos del tabaco pueden causar algunos tipos de cáncer, entre ellos el CCU. Ni las hojas de tabaco ni los químicos que se le añaden son seguros. (Biblioteca Nacional de Medicina de los Estados Unidos, 2018) 


\section{Medidas asociadas a la reducción del riesgo de cáncer de cuello uterino}

Vol. 3, núm. 1., (2019)

Miguel Andre Zapata Mata; Rubí Alisba Borja Torres; José Ignacio Macías Alcívar; Erika

Claribel Albán Estrada

Un sistema inmunitario debilitado

"El virus de inmunodeficiencia humana (VIH o HIV, en inglés), el virus que causa el SIDA (AIDS), provoca daño al sistema inmunitario de las mujeres y ocasiona que estén en un mayor riesgo de infecciones por VPH”. La importancia del sistema inmunitario radica en que si este está débil no puede destruir las células cancerosas, ni retardar su crecimiento y extensión. En este tipo de mujeres el cáncer puede avanzar con mayor rapidez de lo normal. (American Cancer Society, 2016)

Un sistema inmunitario puede debilitarse además por el uso de medicamentos que lo suprimen o por un trasplante de órganos.

\section{Infección con clamidia}

La Clamidia es una clase bastante común de bacteria capaz de infectar el sistema reproductor, la cual es transmitida por contacto sexual y puede causar inflamación de la pelvis. "Algunos estudios han indicado que las mujeres cuyos resultados de análisis de sangre y mucosidad del cuello uterino muestran evidencia de una infección pasada o actual con clamidia tienen mayor riesgo de cáncer de cuello uterino”. (American Cancer Society, 2016)

Una alimentación con pocas frutas y verduras

"Las mujeres con una alimentación que no incluya suficientes frutas, ensaladas y verduras pueden tener un mayor riesgo de cáncer de cuello uterino”. (American Cancer Society, 2016) 


\section{Medidas asociadas a la reducción del riesgo de cáncer de cuello uterino}

Vol. 3, núm. 1., (2019)

Miguel Andre Zapata Mata; Rubí Alisba Borja Torres; José Ignacio Macías Alcívar; Erika Claribel Albán Estrada

\section{Tener sobrepeso}

"Las mujeres que tienen sobrepeso tienen una mayor probabilidad de padecer adenocarcinoma del cuello uterino”. (American Cancer Society, 2016)

\section{Uso prolongado de anticonceptivos orales}

Existe evidencia de que el uso prolongado de píldoras anticonceptivas aumenta el riesgo de CCU. "La investigación sugiere que el riesgo de cáncer de cuello uterino aumenta mientras más tiempo una mujer tome las píldoras, pero el riesgo se reduce nuevamente después de suspender las píldoras, y regresa a lo normal aproximadamente 10 años después de suspenderlas". (American Cancer Society, 2016)

\section{Uso de un dispositivo intrauterino}

Algunos estudios sugieren que las mujeres que usaron un dispositivo intrauterino presentaban un menor riesgo de CCU. "El efecto en el riesgo se observó incluso en mujeres que tuvieron un dispositivo intrauterino por menos de un año, y el efecto protector permaneció después de remover los dispositivos”. (American Cancer Society, 2016)

\section{Tener muchos embarazos a término}

Aquellas mujeres que han tenido tres o más embarazos a término tienen un mayor riesgo de padecer CCU. Asimismo, algunos estudios indican que los cambios hormonales durante el embarazo podrían ocasionar que las mujeres durante ese período estén más susceptibles a infección con VPH o algún crecimiento tumoral. A todo esto, se aúna la creencia de que las 


\section{Medidas asociadas a la reducción del riesgo de cáncer de cuello uterino}

Vol. 3, núm. 1., (2019)

Miguel Andre Zapata Mata; Rubí Alisba Borja Torres; José Ignacio Macías Alcívar; Erika

Claribel Albán Estrada

mujeres embarazadas podrían tener sistemas inmunitarios más débiles. (American Cancer Society, 2016)

Tener menos de 17 años en el primer embarazo a término

Embarazos precoces como las mujeres que tuvieron su primer embarazo a término a la edad de 17 años o menos, duplican aproximadamente por dos la probabilidad de llegar a contraer CCU, esto en comparación con mujeres que tuvieron su primer embarazo a los 25 años o después. (American Cancer Society, 2016)

\section{Situación económica}

"Muchas mujeres con bajos ingresos no tienen acceso fácil a servicios adecuados de atención a la salud, incluyendo las pruebas de Papanicolaou". Esta realidad dificulta que las mujeres ubicadas en un estrato social con bajos recursos tengan el acceso a las diferentes pruebas de detección, ni mucho menos que reciban el tratamiento adecuado para combatir precánceres de cuello uterino. (American Cancer Society, 2016)

\section{Dietilestilbestrol (DES)}

Es un fármaco hormonal que se administró a algunas mujeres entre el periodo 1.940 y 1.971 con la finalidad de prevenir el aborto espontáneo. El grupo de mujeres nacidas de madres a las cuales le fueron administradas este medicamento podrían padecer de adenocarcinoma de células claras de la vagina o del cuello uterino más frecuentemente de lo esperado. "Existe alrededor de un caso de adenocarcinoma de células claras del cuello uterino o de la vagina por 


\section{Medidas asociadas a la reducción del riesgo de cáncer de cuello uterino}

Vol. 3, núm. 1., (2019)

Miguel Andre Zapata Mata; Rubí Alisba Borja Torres; José Ignacio Macías Alcívar; Erika Claribel Albán Estrada

cada 1,000 mujeres cuyas madres tomaron DES durante el embarazo". Esto es que cerca del 99.9\% de este grupo de mujeres no padecen de estos cánceres. (American Cancer Society, 2016)

Antecedente familiar de cáncer de cuello uterino

El factor de los antecedentes familiares, es decir, si una madre o hermana tuvieron CCU, las probabilidades de padecer esta enfermedad aumentan, comparados con aquellos casos en que la mujer no tiene estos antecedentes. Ciertos investigadores tienen la sospecha de que algunos casos de este aumento del riesgo por antecedentes familiares se deben a una condición hereditaria que ocasiona en algunas mujeres una disminución en la capacidad de combatir la infección por VPH. (American Cancer Society, 2016)

\section{Prevención del CCU}

La prevención del cáncer consiste en un conjunto de medidas las cuales están dirigidas a reducir la posibilidad de enfermar. La prevención del CCU no sólo reduce el número de la enfermedad, sino que disminuye el número de muertes que causa el cáncer. La principal estrategia para la disminución del cáncer es el análisis de los factores de riesgo, así como de los factores que puedan servir de protección.

Algunos factores de riesgo de cáncer se pueden evitar, mientras que otros no. Por ejemplo, tanto fumar como heredar ciertos genes son factores de riesgo para ciertos tipos de cáncer, pero solo se puede evitar fumar. El ejercicio regular y una alimentación saludable pueden ser factores de protección contra ciertos tipos de cáncer. También es importante mencionar que existe la posibilidad de que al evitar los factores de riesgo e incrementar los de protección 


\section{Medidas asociadas a la reducción del riesgo de cáncer de cuello uterino}

Vol. 3, núm. 1., (2019)

Miguel Andre Zapata Mata; Rubí Alisba Borja Torres; José Ignacio Macías Alcívar; Erika

Claribel Albán Estrada

disminuya considerablemente el riesgo, no obstante, no es una garantía para que las personas no enfermen de cáncer. Existen diversas formas de prevenir el cáncer, sobre las cuales cada día se realizan nuevos estudios, cambiar el estilo de vida o crear hábitos de alimentación saludables, evitar todo lo que cause cáncer, así como el adecuado tratamiento para una afección precancerosa todo en dirección de que se evite el cáncer. (Instituto Nacional del Cáncer de los Estados Unidos, 2019)

La triada de la prevención contra el CCU está constituida por la vacunación contra el VPH, la detección temprana de precáncer y el tratamiento de lesiones precancerosas. No obstante, existen una serie de medidas adicionales cuya integración a la población femenina son fundamentales para la prevención de esta enfermedad.

\section{Vacunarse contra el VPH}

"Más del 90\% de los CCU se asocian a la infección por VPH, además de otros cánceres como el $60 \%$ de los cánceres orofaríngeos, $91 \%$ cáncer de pene, $75 \%$ cáncer de vagina y el $69 \%$ de los cánceres de vulva”. (Sociedad Española de Oncología Médica, 2018)

Existe una vacuna disponible para la protección contra los tipos de VPH que ocasionan la mayoría de los cánceres de cérvix. Esta vacuna está recomendada para las niñas y mujeres de 9 a 26 años de edad. Su forma de administración consta de una serie de 2 inyecciones a las niñas de 9 a 14 años de edad y 3 inyecciones en adolescentes que superan los 14 años de edad. Es conveniente que las niñas reciban la vacuna antes de cumplir los 11 años o antes de tener una vida sexualmente activa, sin ser este último una limitante para su administración. (Biblioteca Nacional de Medicina de los Estados Unidos, 2019) 


\section{Medidas asociadas a la reducción del riesgo de cáncer de cuello uterino}

Vol. 3, núm. 1., (2019)

Miguel Andre Zapata Mata; Rubí Alisba Borja Torres; José Ignacio Macías Alcívar; Erika Claribel Albán Estrada

Verdaderamente la vacuna contra el VPH constituye uno de los más grandes avances científicos de nuestra era en cuanto a la prevención primaria. Esta vacunación de niñas en edades entre 11-14 años ha sido incluida dentro del calendario vacunal. "En el 2016 la Sociedad Americana de Oncología Médica (ASCO) hizo pública la recomendación de vacunar a todas las niñas y niños entre 11 y 12 años frente al HPV”, además de destacar la importancia de asegurar la vacunación mundial por medio de una adecuada educación, una adecuación de sistemas sanitarios, de recursos y de seguir las investigaciones en el campo. (Sociedad Española de Oncología Médica, 2018)

Por otra parte, Medina, Morales, \& Sierra, (2018) citan a Drolet y cols., (2015), los cuales demostraron en una revisión sistemática sobre la vacunación contra el VPH, la existencia de “evidencia suficiente (después de analizar múltiples ensayos clínicos y su aplicación en 64 países, 4 regiones y 12 territorios) para sostener, que la inmunidad generada tras su aplicación produce fuerte protección en pacientes VPH al menos hasta los 55 años”. Asimismo, acotan que la vacuna protege ante la aparición de varios cánceres vinculados al virus para ambos sexos, además de que condiciona un espaciamiento en los tiempos de cribado. (p. 89)

\section{Detección temprana de precánceres de cuello uterino}

Una de las formas más comprobadas de prevenir el CCU consiste en hacerse pruebas de detección, detectar a tiempo alguna anormalidad en el organismo aumenta los márgenes de disminución de la aparición o del desarrollo de la enfermedad. Realizar estas pruebas permite identificar afecciones que podrían resultar en precánceres los cuales pueden ser detectados 


\section{Medidas asociadas a la reducción del riesgo de cáncer de cuello uterino}

Vol. 3, núm. 1., (2019)

Miguel Andre Zapata Mata; Rubí Alisba Borja Torres; José Ignacio Macías Alcívar; Erika

Claribel Albán Estrada

mucho antes de que se conviertan en cánceres. En caso de encontrarse un precáncer, existe la posibilidad de ser tratado con la finalidad de prevenir el CCU. (American Cáncer Society, 2019)

Existen tres pruebas básicas para detectar lesiones precancerosas, las cuales pueden ser tratadas para evitar la aparición del CCU, estas son la prueba del VPH, el Papanicolau, Pap o Citología y la Inspección Visual con Ácido Acético (IVAA).

Es importante mencionar que desde 1.940 el porcentaje de muertes por CCU ha disminuido un $70 \%$ en países desarrollados, esto gracias al efecto del cribado con el test de Papanicolau, aunado al tratamiento de la lesión o primera fase de la enfermedad. "Hoy en día en el diagnóstico precoz del cáncer de cérvix debe realizarse una citología, así como la determinación de VPH”. (Sociedad Española de Oncología Médica, 2018)

\section{1.- Prueba del Virus de Papiloma Humano}

Esta prueba sirve para detectar infecciones ocasionadas por algunos tipos de VPH causantes del cáncer, así como identificar a aquellas mujeres que corren riesgo de CCU. Está basada en la detección de VPH, así como de sus tipos, tanto de bajo como de alto riesgo en muestras vaginales y/o cervicales. (Organización Panamericana de la Salud, 2019)

\section{2.- Papanicolau, Pap o Citología:}

El examen ginecológico conjuntamente con la prueba de PAP o citología permiten detectar variaciones en las células del cuello uterino causadas por el VPH con la finalidad de determinar alguna anormalidad. Este es un método utilizado con mayor frecuencia. (Organización Panamericana de la Salud, 2019) 


\section{Medidas asociadas a la reducción del riesgo de cáncer de cuello uterino}

Vol. 3, núm. 1., (2019)

Miguel Andre Zapata Mata; Rubí Alisba Borja Torres; José Ignacio Macías Alcívar; Erika Claribel Albán Estrada

Es importante comenzar la práctica de citologías vaginales a los 21 años, posteriormente, las mujeres de 21 a 29 años deberán realizarse una citología cada 3 años. Para la edad comprendida entre 30 a 65 años deberán examinarse ya sea con una citología vaginal cada 3 años o bien un examen del VPH cada 5 años. En el caso de las mujeres de 65 a 70 años pueden dejar de practicarse citologías vaginales, solo en aquellos casos en donde durante los últimos 10 años, hayan tenido tres pruebas negativas. Para aquellas mujeres a las que se les hayan detectado y tratado un precáncer deberán continuar realizándose citologías por 20 años, posterior a dicho tratamiento o hasta los 65 años de edad. (Biblioteca Nacional de Medicina de los Estados Unidos, 2019)

\section{3.- Inspección Visual con Ácido Acético (IVAA)}

Esta inspección visual con ácido acético es el método mediante el cual se detectan cambios tempranos en las células, los cuales son visibles al usar un espéculo para inspeccionar el cérvix, posterior a la aplicación de una solución diluida de ácido acético, en el momento de un examen ginecológico. Estos resultados son inmediatos. (Organización Panamericana de la Salud, 2019)

En aquellos casos en donde los resultados de estos exámenes son anormales, es imperioso que la mujer se practique otros exámenes indicados por su ginecólogo o algún tratamiento que este indique. Estas pruebas y los tratamientos para detectar el precáncer son seguros, además de efectivos para la prevención del cáncer. (Organización Panamericana de la Salud, 2019) 


\section{Medidas asociadas a la reducción del riesgo de cáncer de cuello uterino}

Vol. 3, núm. 1., (2019)

Miguel Andre Zapata Mata; Rubí Alisba Borja Torres; José Ignacio Macías Alcívar; Erika

Claribel Albán Estrada

\section{Tratamiento de lesiones precancerosas}

Crioterapia: "Es el congelamiento y destrucción de las áreas anormales del cérvix mediante la aplicación de una sonda de metal enfriada con nitrógeno líquido o dióxido de carbono directamente en el cuello uterino". Por lo general ocasiona algunos calambres. Si como consecuencia de este tratamiento la mujer presenta otras complicaciones, inmediatamente deberá acudir al centro de salud o clínica, caso contrario, para su control deberá repetir una prueba de detección del cáncer cervicouterino a los 12 meses. (Organización Panamericana de la Salud, 2019, p. 4)

LEEP: "Es un procedimiento para extirpar el tejido anormal mediante un alambre delgado que se calienta con corriente eléctrica. Se realiza bajo anestesia local. Normalmente solo causa algunos calambres, o sangrado leve a moderado durante algunas semanas". (Organización Panamericana de la Salud, 2019, p. 4)

\section{Otras recomendaciones}

No fume. El fumar cigarrillo incrementa el riesgo de contraer cáncer de cuello uterino. Tenga prácticas sexuales seguras, siempre use condones, sin embargo, tenga en cuenta que estos no protegen del todo, ya que el virus o las verrugas pueden encontrarse en áreas de la piel circundante al órgano sexual. Es importante tener una sola pareja sexual, de la cual se tenga la confianza de que está libre de la infección. Limitar la cantidad de parejas sexuales a lo largo del tiempo es fundamental para reducir los riesgos de enfermarse. (Biblioteca Nacional de Medicina de los Estados Unidos, 2019) 


\section{Medidas asociadas a la reducción del riesgo de cáncer de cuello uterino}

Vol. 3, núm. 1., (2019)

Miguel Andre Zapata Mata; Rubí Alisba Borja Torres; José Ignacio Macías Alcívar; Erika Claribel Albán Estrada

"Las buenas elecciones alimentarias pueden fortalecer su sistema inmunitario y pueden ayudar a protegerlo del cáncer. Los productos químicos y los endulzantes añadidos a ciertas comidas se están estudiando por su posible vínculo con el cáncer”. (Biblioteca Nacional de Medicina de los Estados Unidos, 2018)

Mantener un peso saludable es importante para disminuir riesgos de CCU. "Se han realizado estudios que demostraron que las personas que hacen ejercicio parecen tener un menor riesgo de padecer ciertos tipos de cáncer". (Biblioteca Nacional de Medicina de los Estados Unidos, 2018)

\section{Conclusiones.}

Las medidas asociadas a la reducción del riesgo de CCU concentra tres herramientas básicas: la vacunación contra el VPH, la detección temprana de precáncer de cuello uterino y el tratamiento de lesiones precancerosas. A este trípode se unen la evasión de los factores de riesgo controlables como lo son el tabaquismo, las prácticas sexuales inseguras, el sobre peso, la inactividad física, la mala alimentación, entre los principales.

Identificar y abordar con énfasis la población con factores de riesgo es fundamental como estrategia de reducción de la aparición de la enfermedad y de muertes por esta causa.

Los Estados deben asumir la responsabilidad de ofrecer, a través del sistema de salud las herramientas necesarias a la población, especialmente la de menos recursos económicos, para acceder a los exámenes de detección temprana, así como a las vacunas de VPH y los diferentes tratamientos de lesiones precancerosas. 


\section{Medidas asociadas a la reducción del riesgo de cáncer de cuello uterino}

Vol. 3, núm. 1., (2019)

Miguel Andre Zapata Mata; Rubí Alisba Borja Torres; José Ignacio Macías Alcívar; Erika

Claribel Albán Estrada

El conocimiento que la población femenina pueda manejar acerca de la enfermedad y su prevención es fundamental y el hábito de una revisión ginecológica constante y oportuna puede evitar el CCU, reducir los márgenes desastrosos de esta problemática de salud mundial y brindar una mejor calidad de vida a las mujeres en todo el mundo.

\section{Referencias Bibliográficas.}

American Cancer Society. (16 de Noviembre de 2016). Recuperado el 26 de Abril de 2019, de https://www.cancer.org/es/cancer/cancer-de-cuello-uterino/causas-riesgosprevencion/factores-de-riesgo.html

American Cáncer Society. (23 de Enero de 2019). cancer.org. Recuperado el 26 de Abril de 2019, de https://www.cancer.org/es/cancer/cancer-de-cuello-uterino/causas-riesgosprevencion/prevencion.html

Biblioteca Nacional de Medicina de los Estados Unidos. (22 de Mayo de 2018). MedlinePlus. $\begin{array}{llllll}\text { Recuperado el } & 25 & \text { de } & \text { Abril de }\end{array}$ https://medlineplus.gov/spanish/cervicalcancer.html

Biblioteca Nacional de Medicina de los Estados Unidos. (26 de Julio de 2018). MedlinePlus. $\begin{array}{llllll}\text { Recuperado el } & 26 & \text { de } & \text { Abril de }\end{array}$ https://medlineplus.gov/spanish/ency/patientinstructions/000825.htm

Biblioteca Nacional de Medicina de los Estados Unidos. (01 de Abril de 2019). MedlinePlus. $\begin{array}{llllll}\text { Recuperado el } 26 & \text { de } & \text { Abril }\end{array}$ https://medlineplus.gov/spanish/ency/patientinstructions/000419.htm

Instituto Nacional del Cáncer de los Estados Unidos. (09 de Abril de 2019). Institutos Nacionales de la Salud de Estados Unidos. Recuperado el 26 de Abril de 2019, de https://www.cancer.gov/espanol/tipos/cuello-uterino/paciente/prevencion-cuello-uterinopdq\#section/all

Instituto Nacional del Cáncer de los Estados Unidos. (14 de Marzo de 2019). Institutos Nacionales de la Salud de Estados Unidos. Recuperado el 26 de Abril de 2019, de https://www.cancer.gov/espanol/tipos/cuello-uterino/pro/prevencion-cuello-uterino-pdq

Instituto Nacional del Cáncer de los Estados Unidos. (17 de Abril de 2019). Institutos Nacionales de Salud de los Estados Unidos. Recuperado el 23 de Abril de 2019, de https://www.cancer.gov/espanol/tipos/cuello-uterino/paciente/tratamiento-cuello-uterinopdq 


\section{Medidas asociadas a la reducción del riesgo de cáncer de cuello uterino}

Vol. 3, núm. 1., (2019)

Miguel Andre Zapata Mata; Rubí Alisba Borja Torres; José Ignacio Macías Alcívar; Erika Claribel Albán Estrada

Medina, V. M., Morales, R., \& Sierra, L. (22 de Marzo de 2018). Cáncer cervicouterino. Desigual avance entre prevención, diagnóstico precoz y tratamiento. Finlay, 8(2), 88-90. Recuperado el 26 de Abril de 2019, de http://scielo.sld.cu/pdf/rf/v8n2/rf02208.pdf

Organización Mundial de la Salud. (24 de Enero de 2019). Organización Mundial de la Salud. Recuperado el 26 de Abril de 2019, de https://www.who.int/es/news-room/factsheets/detail/human-papillomavirus-(hpv)-and-cervical-cancer

Organización Panamericana de la Salud. (28 de Septiembre de 2017). paho.org. Recuperado el 26 de Abril de 2019, de https://www.paho.org/hq/index.php?option=com_content $\& v i e w=\operatorname{article} \& i d=13746:$ count ries-report-progress-on-preventing-controlling-cervical-cancer\&Itemid=42440\&lang=es

Organización Panamericana de la Salud. (2019). PRUEBAS DE DETECCIÓN TEMPRANA DEL CÁNCER CERVICOUTERINO. Organización Mundial de la Salud. Recuperado el 26 de Abril de 2019, de https://www.paho.org/hq/index.php?option=com_docman\&view=download\&category_sl ug=hojas-informativas-3577\&alias=32864-hoja-informativa-4-pruebas-detecciontemprana-cancer-cervicouterino-864\&Itemid=270\&lang=es

Ríos, R. (09 de 2017). www.eumed.net. (E. Grupo de investigación (SEJ 309) eumed.net de la Universidad de Málaga, Ed.) Obtenido de www.eumed.net: http://www.eumed.net/libros/libro.php?id=1662

Sociedad Española de Oncología Médica. (20 de Marzo de 2018). seom.org. Recuperado el 26 de Abril de 2019, de https://seom.org/los-avances-en-cancer-de-cervix 